\title{
MutS as a tool for mutation detection`
}

\author{
Anna Stanisławska-Sachadyn and Paweł Sachadyn ${ }^{\bowtie}$ \\ Department of Microbiology, Gdańsk University of Technology, Gdańsk, Poland;

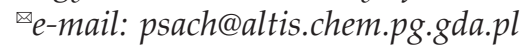

Received: 15 March, 2005; revised: 14 July, 2005; accepted: 22 July, 2005

available on-line: 04 August, 2005

\begin{abstract}
MutS, a DNA mismatch-binding protein, seems to be a promising tool for mutation detection. We present three MutS based approaches to the detection of point mutations: DNA retardation, protection of mismatched DNA against exonuclease digestion, and chimeric MutS proteins. DNA retardation in polyacrylamide gels stained with SYBR-Gold allows mutation detection using 1-3 $\mu \mathrm{g}$ of Thermus thermophilus his ${ }_{6}$-MutS protein and 50-200 ng of a PCR product. The method enables the search for a broad range of mutations: from single up to several nucleotide, as mutations over three nucleotides could be detected in electrophoresis without MutS, due to the mobility shift caused by large insertion/deletion loops in heteroduplex DNA. The binding of DNA mismatches by MutS protects the complexed DNA against exonuclease digestion. The direct addition of the fluorescent dye, SYBR-Gold, allows mutation detection in a single-tube assay. The limited efficiency of T4 DNA polymerase as an exonuclease hampers the application of the method in practice. The assay required 300-400 ng of PCR products in the range of $200-700 \mathrm{bp}$ and 1-3 $\mu \mathrm{g}$ of MutS. MutS binding to mismatched DNA immobilised on a solid phase can be observed thanks to the activity of a reporter domain linked to MutS. We obtained chimeric bifunctional proteins consisting of $T$. thermophilus MutS and reporter domains, like $\beta$-galactosidase or GFP. Very low detection limits for $\beta$-galactosidase could theoretically enable mutation detection not only by the examination of PCR products, but even of genomic DNA.
\end{abstract}

Keywords: MutS, fusion, chimeric protein, mutation detection, SNP

MUTATIONS

Single nucleotide polymorphisms (SNPs) account for thousands of genetic diseases and neoplasms, which are reported to afflict almost $40 \%$ of the human population (Connor \& Ferguson-Smith, 1997). SNP detection and genotyping may be helpful in the diagnosis, therapy and prophylaxis of thousands of single gene disorders, numerous multifactorial diseases and neoplasms; it also could be invaluable in the prediction and elimination of drug side effects (Roses, 2001). Although individual genetic disorders are rare, collectively they comprise over 15500 recognized diseases (McKusick, 1994). DNA sequencing is a gold standard to detect mutations, but the approach is relatively expensive and laborious. If a huge number of samples should be examined, applying a cheap and rapid screening method could be useful to select the mutant samples for the sequencing analysis. Numerous solutions have been proposed to introduce a cheap, rapid and reliable method for mutation analysis, and it seems there is still a demand for improvement. MutS, mismatch binding protein, as a natural guard of replication fidelity, appears to be an excellent tool for the detection of point mutations.

\section{MutS}

In vivo, MutS and other mismatch binding proteins, are the key elements of DNA repair systems, which trigger the sequence of events resulting in the correction of the mismatched site. In the bacterial DNA repair systems, the MutS binding to the DNA mismatch is the first signal. Then, the MutL protein joins MutS-DNA complex and activates the MutH protein. $\mathrm{MutH}$, an endonuclease, cuts the non-methylated strand within a hemimethylated GATC sequence, even up to 1000 bp upstream or downstream of the mismatch. The further repair process includes exonucleolytic digestion of the non-methylated DNA strand. The exonuclease digestion proceeds from the cutting site towards

^Presented at the International Review Conference on Biotechnology, Vienna, Austria, November 2004.

Abbreviations: GFP, green fluorescent protein; SNP, single nucleotide polymorphism. 
the incomplementarity. The digestion is completed a few nucleotides following the mispaired bases by 5'-3' exonuclease VII and exonuclease RecJ and 3'-5' exonuclease I. The resynthesis of the removed strand is carried out by DNA polymerase III holoenzyme. DNA ligase completes the repair process by the formation of phosphodiester bonds in the DNA strand (Modrich, 1991; Au et al., 1992; Allen et al., 1997).

In vitro, MutS recognises mispaired bases and unpaired bases, small DNA insertion/deletion loops of one to three (Whitehouse et al., 1997), four (Parker \& Marinus, 1992) or five nucleotides (StanisławskaSachadyn et al., 2005). MutS also binds damaged DNA, like DNA adducts (Duckett et al., 1996; Johnson et al., 1999). $\mathrm{Mg}^{2+}$ is the only factor required for mismatch binding. Adenine nucleotides like ATP or ADP reduce MutS binding to complementary DNA (Blackwell et al., 2001). DNase footprinting analysis revealed that Thermus aquaticus MutS protects a 24-28 bp region symmetrical around the mismatch (Biswas \& Hsieh, 1997). Crystal structure analyses have revealed the MutS amino-acid residues contacting an approx. $15 \mathrm{bp}$ DNA region around the mismatch (Lamers et al., 2000; Obmolova et al., 2000).

The efficiency of mismatch binding may depend on the MutS origin, mismatch type and the sequence context (Brown et al., 2001; Joshi \& Rao, 2001). Escherichia coli MutS is reported to repair efficiently G:T, A:C, A:A, G:G mismatches, T:T, T:C and $A: G$ repair depends on the nucleotide sequence context (Su et al., 1988), C:C is repaired at a very low level and the repair is probably MutS independent (Nakahara et al., 2000). T. thermophilus MutS is reported to recognise $\mathrm{T}: \mathrm{T}$ and $\mathrm{C}: \mathrm{T}$ mismatches most efficiently, the recognition of $C: C, G: T, G: G, G: A, C$ : $\mathrm{A}$, and A:A mismatches is less efficient (Whitehouse et al., 1997).

The size of bacterial MutS monomers exceeds $90 \mathrm{kDa}$. MutS binds DNA mismatches as a structural heterodimer (Lamers et al., 2000; Obmolova et al., 2000), which means that two identical MutS subunits acquire different conformations after DNA mismatch binding, as revealed by the crystal structures. MutS with the intact C-terminus forms tetramers assembled from two dimers (Bjornson et al., 2003; Stanisławska-Sachadyn et al., 2003). The N-terminal part of MutS is responsible for the mismatch recognition; the C-terminal part containing an ATPase domain, for oligomerization. The N-terminus of the protein is flexible and protruding, whereas the structure of the very C-terminus remains unknown because the MutS crystals were obtained after the truncation of 32 (E. coli, Lamers et al., 2000) or 46 (T. aquaticus, Obmolova et al., 2000) C-terminal amino-acid residues, which are responsible for the tetramer formation, but are dispensable to form a dimer (Biswas et al., 2001).
C- and N-terminal MutS functional fusions have been constructed and reported to maintain the ability of mismatch recognition: the N-terminal MutS fusions with the oligohistidine tag (Feng \& Winkler, 1995; Worth et al., 1998; Wu \& Marinus, 1999); MutS fusions with larger domains like the $40 \mathrm{kDa} \mathrm{MBP}$, maltose binding protein (Gotoh et al., 2000; Biswas et al., 1999), and the Trx-Streptag domain of around 30 kDa (Bi et al., 2003).

\section{EUKARYOTIC MutS HOMOLOGUES}

In eukaryotes, multiple MutS homologues have been identified: MSH1, MSH2, MSH3, MSH4, MSH5, MSH6. Unlike the prokaryotic MutS, the yeast and mammalian homologues have specialised roles. The MSH2/MSH3 heterodimer, known as MutS $\beta$, preferentially binds 2-4 nucleotide insertion/deletion loops, while MSH2/MSH6, known as MutS $\alpha$, preferentially binds base/base mismatches and one base insertion/deletion loops. MSH4 and MSH5 stimulate meiotic crossover and do not appear to function in mutation avoidance (Buermeyer et al., 1999). MSH1 is required for the normal function of Saccharomyces cerevisiae and protects against base pair substitutions and frameshifts in the mitochondrial genome; mammalian MSH1 homologues have not been found so far.

\section{ARCHAEAL MutS HOMOLOGUES}

Archaeal genomes contain the nucleotide sequences encoding proteins of significant homology to bacterial MutS proteins, e.g.: Pyrococcus furiosus (Genbank accesssion number UCHGR_2261), Methanothermobacter thermautotrophicus (AE000931), and Halobacterium sp. NRC-1. It is intriguing that though the genomes of Pyrococcus furiosus, Pyrococcus abyssi, and Pyrococcus horikoshii have been sequenced no nucleotide sequence encoding a protein of significant homology to MutL and MutH has been found. Another archeon, the halophile Halobacterium (Genbank accession number AAG18777, AE004982.1) has three genes encoding proteins of significant homology to MutS: MutS1 - 871 amino acids (AAG18781, AE004982.1), MutS2 - 863 amino acids (AAG18788, AE004983.1) and MutS3 - 669 amino acids (AAG20386.1, AE005111.1). Although the full nucleotide sequence of Halobacterium sp. NRC-1 genome is known, none nucleotide sequence encoding a protein of significant homology to bacterial MutH has been identified. However, there is a Halobacterium sequence encoding a protein of significant homology to MutL (Genbank accession number AAG18777). These data may suggest that the roles of bacterial 
MutS and of the archaeal homologues are different. A filter-binding assay showed that P. furiosus MutS2 protein binds DNA, but no specific mismatch recognition has been observed (Vijayvargia \& Biswas, 2002).

\section{MutS BASED METHODS FOR MUTATION DETECTION}

In vivo, MutS recognizes premutational changes in genomic DNA. In vitro, mutation detection employing MutS usually includes four steps: PCR amplification of the DNA region containing a mutation, preparation of DNA heteroduplexes, formation of MutS-DNA complexes, and detection of MutS-DNA complexes. The DNA heteroduplex is prepared by mixing equimolar amounts of an examined and a reference PCR product (without mutation), heating to denature DNA, followed by cooling to renature it. The heating and cooling could be repeated several times to mix the examined and reference DNA properly. As the result, the DNA strands from the reference DNA hybridize with the DNA strands from the examined DNA, thus forming DNA heteroduplexes (Fig. 1). If the examined DNA contains a mutation, the DNA heteroduplex is mismatched. If heterozygotic alleles are examined (i.e. one allele contains a mutation, the other does not), the addition of the reference DNA is not necessary (Stanisławska-Sachadyn et al., 2005).

Formation of a MutS-DNA complex may be detected in many ways: direct microscopic observation of complexes using atomic force microscopy,

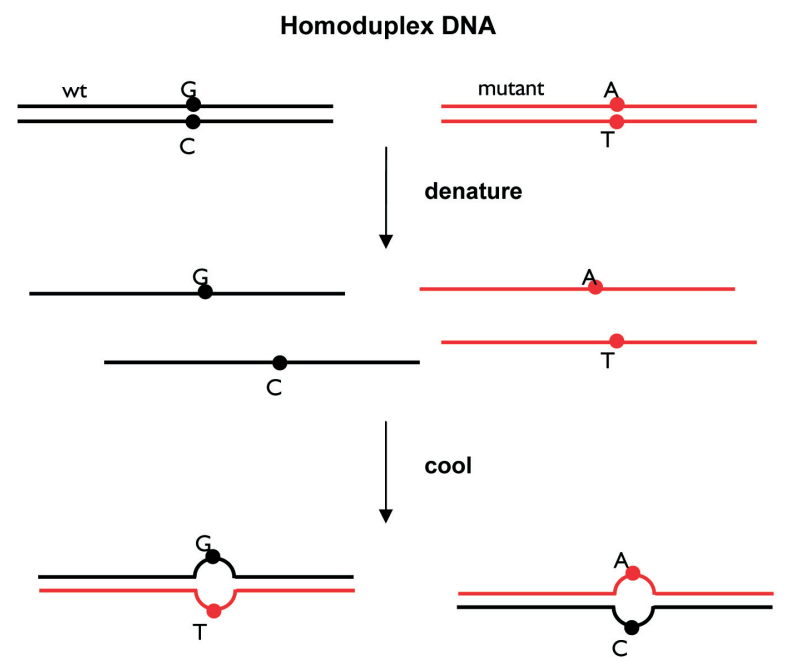

Heteroduplex DNA

Figure 1. The formation of DNA heteroduplexes.

The tested and reference PCR products are mixed, heated and cooled to form heteroduplexes. Single nucleotide differences between the PCR products result in the formation of DNA mismatches (Stanisławska-Sachadyn et al., 2003).
AFM (Sun \& Yokota, 2000), the DNA mobility shift in electrophoresis (Lishanski et al., 1994; Takamatsu et al., 1996; Stanisławska-Sachadyn et al., 2005), DNA protection by MutS against nuclease digestion (Ellis et al., 1994; Sachadyn et al., 2000), the detection of MutS-DNA interactions on a solid phase, including filter assays with radioactive (Whitehouse et al., 1997) or biotin (Wagner, et al., 1995) labelled DNA, and on chip detection (Gotoh et al., 1997; Behrensdorf et al., 2000; Bi et al., 2003). The detection of MutS was enabled by using fluorescent MutS (cyanine labelled) or one fused with reporter domains like a biotinylated tag (Geschwind et al., 1996) or GFP (StanisławskaSachadyn et al., J Biotechnol, accepted).

The proposal to detect mutations directly in genomic DNA by PCR amplification of MutS protected DNA (Parsons \& Heflich, 1997; 1998) is interesting, but the method requires both perfect digestion of non-protected DNA and perfect specificity of MutS binding. The assay enables the enrichment of the mutant sequence approx. 1000-fold.

Mutation detection in PCR products is not the only MutS application. MutS combined with MutL and MutH were used to remove the mutant sequences produced as the result of DNA polymerase errors from PCR products, as MutH digests DNA fragments complexed by MutS (Smith \& Modrich, 1997). A very interesting MutS application is cloning of DNA regions containing point differences, coming from otherwise identical genomes. MutS immobilised on a solid phase was used to capture the mismatched DNA fragments, that represented the point differences between genomes (Gotoh et al., 2000; Wang \& Liu, 2004).

Another group of proteins recognizing mismatched DNA are DNA resolvases. The DNA resolvases recognize not only DNA mismatches, but many other atypical DNA structures like $X$ - and Y-forms, and several nucleotide insertion/deletion loops (Kemper, 1997). Unike MutS, resolvases are endonucleases, which cut the mismatched DNA fragment.

At present, MutS based methods are not commonly applied to mutation analysis, although T. aquaticus thermostable MutS protein was commercially available from Epicentre, and E. coli MutS and MutS based detection kits were offered by Genecheck.

\section{T. thermophilus MutS AS A TOOL FOR MUTATION DETECTION}

In our studies, we decided to explore $T$. thermophilus MutS as a tool for mutation detection. T. thermophilus MutS, although a thermostable protein, recognises mismatches at $60^{\circ} \mathrm{C}$ and at room temperature as well (Takamatsu et al., 1996). The 
other advantage of TthMutS was the ability to recognise all mismatches with similar efficiency. According to the reported data, differences in the efficiency of mismatch recognition dependent on mismatch type are strongly manifested by E. coli MutS, while they are much less pronounced in the case of T. thermophilus MutS. Thus, the efficiency of T. thermophilus MutS binding to the most weakly recognised A:A mismatch was $40 \%$ of that for the best recognised $\mathrm{T}: \mathrm{T}$ mismatch as estimated by filter-binding assay (Whitehouse et al., 1997). The affinities of E. coli MutS for the most weakly recognised C:C and C: $\mathrm{T}$ mismatches were around $10 \%$ of that for the best recognised G:T mismatch as estimated by DNase I footprinting (Su et al., 1988).

We have investigated three approaches for MutS application in SNP analysis: DNA retardation assay, DNA protection assay, and MutS fusions with reporter domains.

\section{DNA RETARDATION}

DNA retardation assay, known as the mobility shift assay or gel-shift assay, is a method commonly employed to the examination of DNA-protein interactions. The method has been already applied to examine DNA-MutS interactions rather, than to detect mutations. The DNA fragments examined in these assays are usually radiolabelled, short DNA fragments (15-30 bp). We used PCR fragments in the range of 200-700 bp. In our assay (StanisławskaSachadyn et al., 2005), the PCR products were neither labelled nor purified prior to examination. The MutS-DNA complexes were electrophoresed in polyacrylamide gels stained with a sensitive fluorescent dye, SYBR-Gold (Fig. 2). The approach allows the detection of DNA mismatches thanks to MuS binding. Mismatches over three nucleotides are reported not to be recognized by MutS (Whitehouse et al., 1997). However, such mismatches are easily detected thanks to the formation of large insertion/deletion loops, which delay the electrophoretic migration, even without MutS complexing. Thus the range of the detected mutations is broadened, as the insertions/deletions over three nucleotides also could be detected in the same assay, yet in a different way.

MutS binds not only DNA mismatches, but fully complementary DNA as well. As MutS covers around 20 nucleotides, the short DNA fragments prepared from two synthesized complementary oligonucleotides (up to $30 \mathrm{bp}$ ) could only contain one binding site for MutS. Thanks to the examination of 262 bp PCR fragments, we could observe some feature of the so called non-specific MutS binding (Stanisławska-Sachadyn et al., 2003). The 262 bp DNA fragments were long enough to be bound by several MutS oligomers, which should result in the

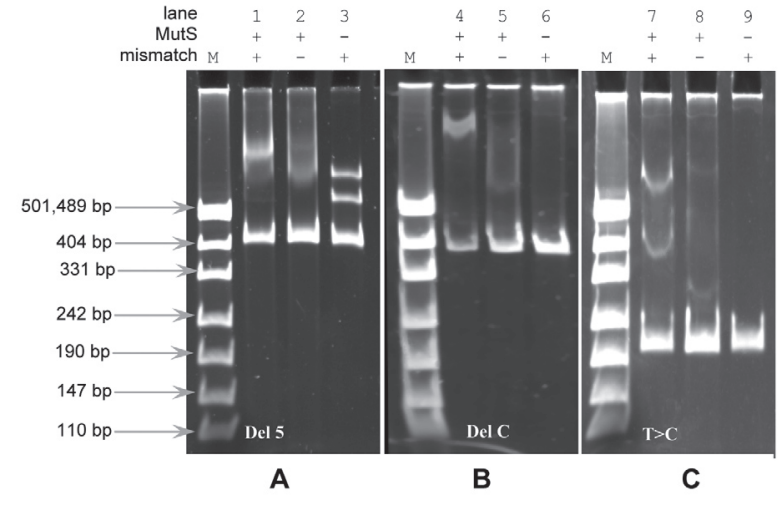

Figure 2. Mutation detection in PCR amplified DNA fragments using Tth his ${ }_{6}$-MutS. Electrophoresis in 5\% polyacrylamide gels stained with SYBR-Gold and photographed using Versa-Doc system (Bio-Rad).

A. MutS retards mismatched DNA containing a five nucleotide bubble resulting from a 5 bp deletion (150-155/ $406 \mathrm{bp}$ ) - lane 1 . The mismatched DNA is also retarded due to the presence of the five nucleotide bubble, without MutS binding (lane 3). B. MutS retards mismatched DNA containing a single nucleotide bubble resulting from one bp deletion (138/284 bp) - lane 4. Fully complementary DNA is also retarded (lane 5), but the intensity of the retarded band is weaker and the migration is faster compared to that of the retarded mismatched DNA. C. MutS retards mismatched DNA containing GT and CA mismatches resulting from a T-C substitution (108/192 bp) - lane 7. Similarly as in the case B: the intensity of the retarded complementary DNA is weaker and the migration is faster (lane 8) compared to that of the retarded mismatched DNA (Stanisławska-Sachadyn et al., 2005).

formation of at least several retarded DNA bands. Even at considerable MutS molar excess (12:1), we observed mostly one retarded DNA band for a fully complementary DNA fragment, which suggests that MutS binds fully complementary DNA at some specific sites (e.g., the ends of a DNA fragment). The fully complementary DNA fragment retarded by MutS migrated faster than a mismatched DNA fragment retarded by MutS, which indicates that the mode of complementary DNA binding is different from that for mismatched DNA.

The DNA retardation assay in polyacrylamide gels stained with SYBR-Gold allowed mutation detection using 1-3 $\mu \mathrm{g}$ of $T$. thermophilus his ${ }_{6}$-MutS protein (obtained in milligram amounts per 1 litre of E. coli culture) and 50-200 ng of a PCR product (Stanisławska-Sachadyn et al., 2005).

\section{MutEX-SYBR-GOLD-MutS DNA PROTECTION ASSAY}

The nucleotide sequence covered by a protein may be identified in footprinting experiments, as it is protected against nuclease digestion (Biswas \& Hsieh, 1997). A similar approach was proposed 
to the mutation detection using MutS. Mismatched DNA fragments were protected by E. coli MutS against the digestion by the T7 DNA polymerase 3 '5 -exonuclease activity. The digestion terminated on each DNA strand at the MutS binding site, the undigested DNA fragments were analysed using capillary electrophoresis (Ellis et al., 1994). In our protection experiments, we employed T4 DNA polymerase as the $3^{\prime}-5^{\prime}$-exonuclease, and T. thermophilus MutS, but the main difference, that we introduced, was the application of SYBR-Gold for direct detection of undigested DNA fragments in the test tube. Thus we created a single-tube assay - the mutation was visualised thanks to the higher fluorescence of the tube containing the undigested mismatched DNA compared with the digested controls of fully complementary DNA (Fig. 3). The system was very promising as shown in model experiments (Sachadyn et al., 2000). Unfortunately the use of the test in routine experiments could be complicated due to the properties of the exonuclease used. Complete digestion of the fully complementary DNA controls required a large excess of the exonuclease. Paradoxically, the DNA exonuclease was contaminated with DNA traces, so the excessive amount of the enzyme added resulted in fluorescence coming from the contaminating DNA. In our opinion the assay is still promising but demands the introduction of a more efficient DNA exonuclease. The assay required around 360 ng of PCR products in the range of 200-700 bp and $1-3 \mu \mathrm{g}$ of MutS.

\section{MutS FUSIONS WITH REPORTER DOMAINS}

The detection of MutS-DNA complexes on a solid phase requires either MutS or DNA to be immobilised. If the protein is immobilised, the DNA bound by MutS should be labelled to be detected. The solution has been applied in a number of studies using nitrocellulose filters and DNA labelling either with radioisotopes or biotin (Whitehouse et al., 1997; Wagner et al., 1995). If DNA is immobilised, MutS bound by DNA should be detected. The MutS captured by the immobilised DNA could be detected using MutS specific antibodies or antibodies directed towards an additional domain fused with MutS (e.g., an oligohistidine tag). However, instead of using antibodies to detect MutS, a reporter domain could be fused to MutS directly. The advantage of this approach is that an enzymatic reporter domain is able to produce a very strong signal (Table 1), so minute amounts of DNA may be examined. Furthermore, the assay would be simplified as one fusion protein would be responsible both for mismatch recognition and signal detection. In fact, MutS possesses an enzymatic activity of ATPase, yet this does not seem to be convenient for rapid, sensitive, and selective detection. We chose alkaline phosphatase and $\beta$-galactosidase as the most useful reporter domain to be fused with MutS for the stability, high catalytic activity and a great selection of chromogenic, fluorogenic and chemiluminescent substrates allowing sensitive detection. Minute amounts of $\beta$ galactosidase: 2 ng - 12000 molecules (Jain \& Magrath, 1991) or $8 \mathrm{fg}-48000$ molecules (Bronstein et al., 1996) have been reported to be detected using a chemiluminescent assay. According to the data presented by Tropix, $4000 \beta$-galactosidase molecules and 30000 alkaline phosphatase molecules could be detected using chemiluminescent reagents (Table 1).

We also designed fusions of MutS with fluorescent proteins like Aequorea victoria green fluorescent protein, GFP (Stanisławska-Sachadyn et al., J Biotechnol, accepted) and red fluorescent protein (DsRed) from an anemone of the genus Discosoma. Though the fluorescent proteins are not detectable

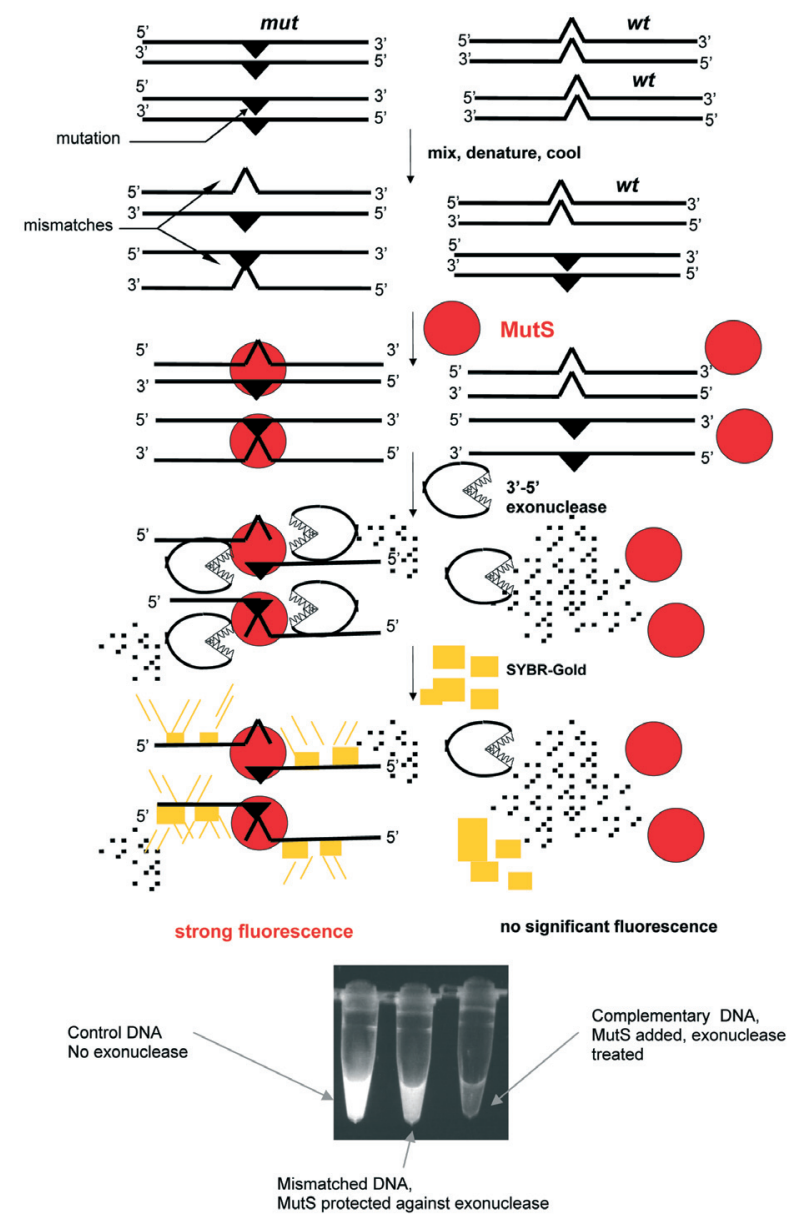

Figure 3. MutEx-SYBR-Gold assay.

The examined DNA (mut) is mixed with reference DNA (wt), the mixture is heated, cooled, then MutS is added, followed by the addition of DNA exonuclease (T4 DNA polymerase). MutS binds to DNA mismatches. The DNA complexed with MutS is partially protected against exonuclease digestion. The results are visualized with a sensitive fluorescent dye (SYBR-Gold) (Sachadyn et al., 2000). 
Table 1. Reporter enzymes and their substrates according to Tropix Products, catalog 1998.

\begin{tabular}{|c|c|c|}
\hline Reporter protein & Detection & Detection limit (protein molecules) \\
\hline \multirow[t]{2}{*}{ Chloramphenicol acetyltransferase (CAT) } & ${ }^{3} \mathrm{H}-$ or ${ }^{14} \mathrm{C}-$ & $5 \times 10^{7}$ \\
\hline & ELISA (colour) & $1 \times 10^{9}$ \\
\hline \multirow[t]{3}{*}{ E. coli $\beta$-galactosidase } & ONPG (colour) & $3 \times 10^{8}$ \\
\hline & MUG (fluorescence) & $6 \times 10^{5}$ \\
\hline & $\begin{array}{l}\text { Galacto-Light }{ }^{\mathrm{TM}} \\
\text { Galacto-Star } \\
\text { (luminescence) }\end{array}$ & $4 \times 10^{3}$ \\
\hline Human growth hormone & $\begin{array}{l}\text { RIA } \\
\text { (isotope) }\end{array}$ & $3 \times 10^{8}$ \\
\hline Glowing worm luciferase & $\begin{array}{l}\text { Dual-Light }{ }^{\circledR} \\
\text { Luc-Screen }^{\mathrm{TM}} \\
\text { (luminescence) }^{\text {(lumes }}\end{array}$ & $10^{3} \times 10^{4}$ \\
\hline \multirow[t]{2}{*}{$\beta$-Glucuronidase (GUS) } & $\begin{array}{l}\text { TUG } \\
\text { (fluorescence) }\end{array}$ & $2 \times 10^{8}$ \\
\hline & $\begin{array}{l}\text { GUS-Light }{ }^{\mathrm{TM}} \\
\text { (luminescence) }\end{array}$ & $5 \times 10^{5}$ \\
\hline \multirow[t]{2}{*}{ Alkaline phosphatase (SEAP) } & $\begin{array}{l}\text { pNPP } \\
\text { (colour) }\end{array}$ & $1 \times 10^{8}$ \\
\hline & $\begin{array}{l}\text { Phospha-Light }{ }^{\mathrm{TM}} \\
\text { (luminescence) }\end{array}$ & $3 \times 10^{4}$ \\
\hline
\end{tabular}

thanks to an enzymatic activity, which allows signal amplification, they do not require any substrates and work in a broad range of conditions. The fluorescent proteins may be detected using fluorescent microscopy with excellent sensitivity, reaching even single molecules (Iwane et al., 1997; Fries et al., 1998; Ku-

Table 2. The chimeric MutS proteins constructed in our studies.

\begin{tabular}{|c|c|c|c|}
\hline his-tag-MutS & & $92 \mathrm{kDa}$ & Active Muts \\
\hline histag-MutS-GFP-histag & $\mathrm{HI}$ & $125 \mathrm{kDa}$ & $\begin{array}{l}\text { Both domains active, } \\
\text { fluorescence 4-5 times weaker } \\
\text { compared with "free" GFP }\end{array}$ \\
\hline histag-GFP-MutS & & $123 \mathrm{kDa}$ & Both domains active \\
\hline histag-MutS-link-GFP-histag & -His-tag & $126 \mathrm{kDa}$ & $\begin{array}{l}\text { Both domains active, } \\
\text { fluorescence 4-5 times weaker } \\
\text { compared with "free" GFP }\end{array}$ \\
\hline histag-Phoa-MutS & & $143 \mathrm{kDa}$ & $\begin{array}{l}\text { Weak activity of alkaline } \\
\text { phosphatase }\end{array}$ \\
\hline histag- $\beta$-Gal-MutS & His-tag & $215 \mathrm{kDa}$ & Proteolytic splitting in E. coli \\
\hline histag-MutS- $\beta$-Gal-histag & -His-tag & $217 \mathrm{kDa}$ & Both domains active \\
\hline histag-MutS-SEAP & & $151 \mathrm{kDa}$ & $\begin{array}{l}\text { Weak activity of alkaline } \\
\text { phosphatase }\end{array}$ \\
\hline histag-SEAP-MutS & & $151 \mathrm{kDa}$ & $\begin{array}{l}\text { Weak activity of alkaline } \\
\text { phosphatase }\end{array}$ \\
\hline histag- MutS-DsRed2 & & $122 \mathrm{kDa}$ & Loss of fluorescence \\
\hline histag-DsRed2-MutS & & $122 \mathrm{kDa}$ & Loss of fluorescence \\
\hline
\end{tabular}

GFP, GFPuv derived from Aequorea victoria; MutS, MutS from T. thermophilus; Phoa, E. coli alkaline phosphatase; $\beta$-Gal, E. coli $\beta$-galactosidase; SEAP (Clontech), secreted human alkaline phosphatase; DsRed2 (Clontech), red fluorescent protein derived from an anemone of Discosoma genus. 

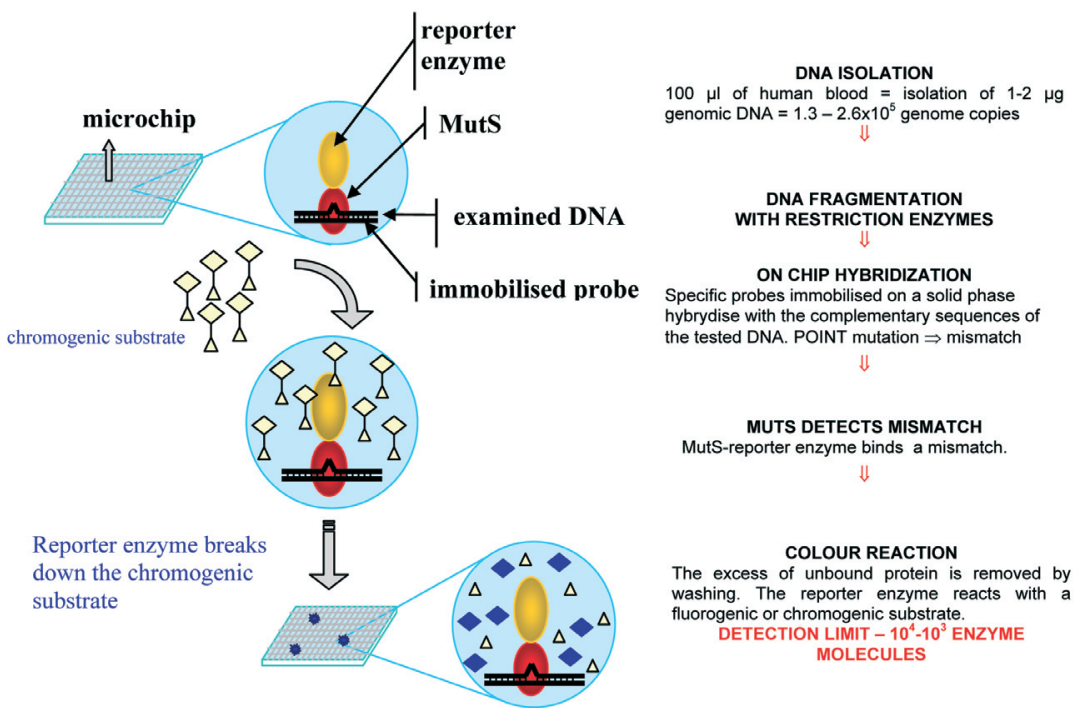

Figure 4. The idea of mutation detection in genomic DNA without PCR amplification using a chimeric MutS protein.

bitscheck et al., 2000). Also microfluidic devices are promising for rapid detection of single molecules (Wabuyele et al., 2001).

We designed and examined a series of fusion proteins summarised in Table 2. The fusion proteins were obtained by in frame cloning of the reporter domain genes into plasmids bearing the $T$. thermophilus mutS gene. The proteins were expressed in E. coli and purified using metal-chellate affinity chromatography.

The fusions with alkaline phosphatase, both bacterial (phoA) and placental (SEAP), exhibited very low alkaline phosphatase activity, thus were useless for the desired purpose. The chimeric protein consisting of $\beta$-galactosidase fused to the MutS N-terminus ( $\beta$-galactosidase-MutS) was split into two parts, probably due to the activation of a cryptic proteolytic site. This process is typical of E. coli $\beta$-galactosidase fused to the $N$-terminus of a large protein (Viaplana et al., 1997; Corchero \& Villaverde, 1999). The fusion of $\beta$-galactosidase to the MutS C-terminus (MutS- $\beta$-galactosidase) was stable, and exhibited both mismatch binding and $\beta$ galactosidase activities (Sachadyn et al., submitted). The $\beta$-galactosidase activity was comparable to that of the native enzyme. The mismatch binding activity was confirmed using DNA retardation assay. The examination of mismatch-binding activity on a solid phase was demanding, because MutS- $\beta$-galactosidase was bound quite efficiently to the ion-exchange membranes and filters applied to DNA immobilisation. MutS- $\beta$-galactosidase was not bound by the plastic microplates coated with avidine that were used for immobilisation of biotinylated DNA. Unfortunately the binding of biotinylated DNA was not efficient enough for a rapid and sensitive assay.
The fusion of T. thermophilus MutS with E. coli $\beta$-galactosidase was the first attempt to obtain a bifunctional chimeric protein exhibiting mismatch binding properties and an enzymatic activity enabling sensitive detection using a colorimetric assay. The fusions with enzymatic reporter domains like $\beta$-galactosidase could be applied to the detection of mutations on ELISA microplates with immobilised DNA or in dotblot systems. The enzymatic domain increases the sensitivity of detection, theoretically enabling even direct detection in genomic DNA, without PCR (Fig. 4). The fusions with fluorescent domains like GFP could be applied in microchip systems.

\section{CONCLUSIONS}

MutS seems to be a promising tool for SNP analysis. The described DNA retardation and DNA protection procedures for mutation detection required a few hundred nanograms of tested DNA and 1-3 $\mu \mathrm{g}$ of MutS. The amount of MutS obtained from 1 litre of $E$. coli culture is a few milligrams, which may be sufficient for thousands of SNP analysis. Unfortunately, MutS interactions with fully complementary DNA complicate the application of MutS to mutation detection. MutS fusion with enzymatic domains, like $\beta$-galactosidase, is an especially interesting solution, as it could increase the sensitivity of detection, hopefully enabling direct mutation detection in genomic DNA.

\section{Acknowledgements}

This study was supported by the State Committee for Scientific Research (project KBN No. 6 P04B 00921. 


\section{REFERENCES}

Allen DJ, Makhov A, Grilley M, Taylor J, Thresher R, Modrich P, Griffith JD (1997) MutS mediates heteroduplex loop formation by a translocation mechanism. EMBO J 16: 4467-4476.

Au KG, Welsh K, Modrich P (1992) Initiation of methyl-directed mismatch repair. J Biol Chem 267: 12142-12148.

Behrensdorf HA, Pignot M, Windhab N, Kappel A (2000) Rapid parallel mutation scanning of gene fragments using a microelectronic protein-DNA chip format. Nucleic Acids Res 30: E64.

Bi LJ, Zhou YF, Zhang XE, Deng JY, Zhang ZP, Xie B, Zhang CG (2003) A MutS-based protein chip for detection of DNA mutations. Anal Chem 75: 4113-4119.

Biswas I, Hsieh P (1997) Interaction of MutS protein with the major and minor grooves of a heteroduplex DNA. J Biol Chem 272: 13355-13364.

Biswas I, Fleming KG, Qin J, Lary JW, Yphantis DA, Yang W, Hsieh P (1999) Oligomerization of a MutS mismatch repair protein from Thermus aquaticus. J Biol Chem 274: 23673-23678.

Biswas I, Obmolova G, Takahashi M, Herr A, Newman MA, Yang W, Hsieh P (2001) Disruption of helix-u-turn-helix motif of MutS protein: loss of subunit dimerization, mismatch binding and ATP hydrolysis. J Mol Biol 305: 805-816.

Bjornson KP, Blackwell LJ, Sage H, Baitinger C, Allen D, Modrich P (2003) Assembly and molecular activities of the MutS tetramer. J Biol Chem 278: 34667-34673.

Blackwell LJ, Bjornson KP, Allen DJ, Modrich P (2001) Distinct MutS DNA-binding modes that are differentially modulated by binding and hydrolysis. J Biol Chem 276: 34339-34347.

Bronstein I, Martin CS, Fortin JJ, Olesen CE, Voyta JC (1996) Chemiluminescence: sensitive detection technology for reporter gene assays. Clin Chem 42: 1542-1546.

Brown J, Brown T, Fox KR (2001) Affinity of mismatchbinding protein MutS for heteroduplexes containing different mismatches. Biochem J 354: 627-633.

Buermeyer AB, Dêschenes SM, Baker SM, Liskay RM (1999) Mammalian DNA mismatch repair. Annu Rev Genet 33: 533-564.

Connor M, Ferguson-Smith M (1997) Essential Medical Genetics, 5th edn, Table 21.1, Blackwell Science, Oxford.

Corchero JL, Villaverde A (1999) Tolerance of Escherichia coli $\beta$-galactosidase C-terminus to different-sized fusions. Biotechnol Bioeng 64: 644-649.

Duckett DR, Drummond JT, Murchie AI, Reardon JT, Sancar A, Lilley DM, Modrich P (1996) Human MutS $\alpha$ recognizes damaged DNA base pairs containing $\mathrm{O}^{6}$-methylguanine, $\mathrm{O}^{4}$-methylthymine, or the cisplatin-d $(\mathrm{GpG})$ adduct. Proc Natl Acad Sci USA 93: 6443-6447.

Ellis LA, Taylor GR, Banks R, Baumberg S (1994) MutS binding protects heteroduplex DNA from exonuclease digestion in vitro: a simple method for detecting mutations. Nucleic Acids Res 22: 2710-2711.

Feng G, Winkler ME (1995) Single step purifications of his $_{6}-\mathrm{MutH}, \mathrm{his}_{6}-\mathrm{MutL}$ and his $_{6}$-MutS repair proteins of Escherichia coli K12. Biotechniques 19: 956-965.

Fries JR, Brand L, Eggeling C, Köllner M, Seidel CAM (1998) Quantitative identification of different single molecules by selective time-resolved confocal fluorescence spectroscopy. J Phys Chem A 102: 6601-6613.

Geschwind DH, Rhee R, Nelson SF (1996) A biotinylated MutS fusion protein and its use in a rapid mutation screening technique. Genet Anal 13: 105-111.

Gotoh M, Hasebe M, Ohira T, Hasegawa Y, Shinohara Y, Sota H, Nakao J, Tosu M (1997) Rapid method for detection of point mutation using mismatch binding protein (MutS) and an optical biosensor. Genet Anal 14: $47-50$.

Gotoh K, Hata M, Miyajima M, Yokota H (2000) Genome wide detection of unknown subtle mutations in bacteria by combination of MutS and RDA. Biochem Biophys Res Commun 268: 535-540.

Iwane AH, Funatsu T, Harada Y, Tokunaga M, Ohara O, Morimoto S, Yanagida T (1997) Single molecular assay of individual ATP turnover by a myosin-GFP fusion protein expressed in vitro. FEBS Lett 407: 235-238.

Jain VK, Magrath, IT (1991) A chemiluminescent assay for quantitation of $\beta$-galactosidase in the femtogram range: application to quantitation of $\beta$-galactosidase in lacZtransfected cells. Anal Biochem 199: 119-124.

Johnson KA, Mierzwa ML, Fink SP, Marnett LJ, Hancock AB Jr (1999) MutS recognition of exocyclic DNA adducts that are endogenous products of lipid oxidation. J Biol Chem 274: 27112-27118.

Joshi A, Rao BJ (2001) MutS recognition: multiple mismatches and sequence context effects. J Biosci 26: 595-606 .

Kemper B (1997) In DNA Damage and Repair. Biochemistry, Genetics and Cell Biology. Nickoloff JA, Hoekstra M, eds, pp 179-204. Humana Press, Totowa, NJ.

Kubitscheck U, Kückmann O, Kues T, Peters R (2000) Imaging and Tracking of Single GFP Molecules in Solution. Biophys J 78: 2170-2179.

Lamers $\mathrm{MH}$, Perrakis A, Enzlin JH, Winterwerp $\mathrm{HH}$, de Wind N, Sixma TK (2000) The crystal structure of mismatch repair protein MutS binding to a GxT mismatch. Nature 407: 711-717.

Lishanski A, Ostrander EA, Rine J (1994) Mutation detection by mismatch binding protein, MutS, in amplified DNA: application to the cystic fibrosis gene. Proc Natl Acad Sci USA 91: 2674-2678.

McKusick VA (1994). Mendelian Inheritance in Man: A Catalog of Human Genetics and Genetic Disorders, 11th edn. The Johns Hopkins University Press, Baltimore.

Modrich, P (1991) Mechanisms and biological effects of mismatch repair. Annu Rev Genet 25: 229-253.

Nakahara T, Zhang, QM, Hashiguchi K, Yonei S (2000) Identification of proteins of Escherichia coli and Saccharomyces cerevisiae that specifically bind to $\mathrm{C} / \mathrm{C}$ mismatches in DNA. Nucleic Acids Res 28: 2551-2556.

Obmolova G, Ban C, Hsieh P, Yang W (2000) Crystal structures of mismatch repair protein MutS and its complex with a substrate DNA. Nature 407: 703-710.

Parker BO, Marinus MG (1992) Repair of DNA heteroduplexes containing small heterologous sequences in Escherichia coli. Proc Natl Acad Sci USA 89: 1730-1734.

Parsons BL, Heflich RH (1997) Evaluation of MutS as a tool for direct measurement of point mutations in genomic DNA. Mutat Res 374: 277-285.

Parsons BL, Heflich RH (1998) Detection of basepair substitution mutation at a frequency of $1 \times 10^{-7}$ by combining two genotypic selection methods, MutEx enrichment and allele-specific competitive blocker PCR. Environ Mol Mutagen 32: 200-211.

Roses AD (2001) Pharmacogenetics. Hum Mol Genet 10: 2261-2267.

Sachadyn P, Stanisławska A, Kur J (2000) One tube mutation detection using sensitive fluorescent dyeing of MutS protected DNA. Nucleic Acids Res 28: E36.

Smith J, Modrich P (1997) Removal of polymerase-produced mutant sequences from PCR products. Proc Natl Acad Sci USA 94: 6847-6850.

Stanisławska-Sachadyn A, Sachadyn P, Jędrzejczak R, Kur $\mathrm{J}$ (2003) Construction and purification of his 6 -Thermus thermophilus MutS protein. Protein Expr Purif 28: 69-77. 
Stanisławska-Sachadyn A, Paszko Z, Kluska A, Skasko E, Sromek M, Balabas A, Janiec-Jankowska A, Wiśniewska A, Kur J, Sachadyn P (2005) Preliminary studies on DNA retardation by MutS applied to the detection of point mutations in clinical samples. Mutat Res 570: 97-103.

Su S, Lahue RS, Au KG, Modrich P (1988) Mispair specificity of methyl-directed DNA mismatch correction in vitro. I Biol Chem 263: 6829-6835.

Sun HB, Yokota H (2000) MutS-mediated detection of DNA mismatches using atomic force microscopy. Anal Chem 72: 3138-3141.

Takamatsu S, Kato R, Kuramitsu S (1996) Mismatch DNA recognition protein from an extremely thermophilic bacterium, Thermus thermophilus HB8. Nucleic Acids Res 4: 640-647.

Viaplana E, Feliu JX, Corchero JL, Villaverde, A (1997) Reversible activation of a cryptic cleavage site within $E$. coli $\beta$-galactosidase in $\beta$-galactosidase fusion proteins. Biochim Biophys Acta 1343: 221-226.

Vijayvargia R, Biswas I (2002) MutS2 family protein from Pyrococcus furiosus. Curr Microbiol 44: 224-228.
Wagner R, Debbie P, Radman M (1995) Mutation detection using immobilized mismatch binding protein (MutS). Nucleic Acids Res 23: 3944-3948.

Wang J, Liu J (2004) Directly fishing out subtle mutations in genomic DNA with histidine-tagged Thermus thermophilus MutS. Mutat Res 547: 41-47.

Wabuyele MB, Ford SM, Stryjewski W, Barrow J, Soper SA (2001) Single molecule detection of double-stranded DNA in poly (methylmethacrylate) and polycarbonate microfluidic devices. Electrophoresis 22: 3939-3948.

Whitehouse A, Deeble J, Parmar R, Taylor GR, Markham AF, Meredith DM (1997) Analysis of the mismatch and insertion/deletion binding properties of Thermus thermophilus, HB8, MutS. Biochem Biophys Res Commun 233: 834-837.

Worth L Jr, Bader T, Yang J, Clark S (1998) Role of MutS ATPase activity in MutS,L-dependent block of in vitro strand transfer. J Biol Chem 273: 23176-23182.

$\mathrm{Wu} \mathrm{TH}$, Marinus MG (1999) Deletion mutation analysis of the mutS Gene in Escherichia coli. J Biol Chem 274: 5948-5952. 